\title{
Do DETERMINISMO PSÍQUICO ÀS ESCOLHAS SUBJETIVAS
}

\author{
Daniela Scheinkman Chatelard ${ }^{\star}$
}

\begin{abstract}
Resumo
O artigo trata da questão do sujeito sobre o qual operamos na psicanálise, sendo diferente daquele sujeito da psicologia clássica; nesta subjetividade estava fundada na consciência e nela se inscreve o eu. Esta visão do subjetivo, a referência à consciência como predominante, fazia parte do discurso psicológico vigente no século XIX. Na mesma veia corre a tradição cartesiana com o cogito: "Penso, logo existo". Desta visão do homem, a categoria da existência está atrelada à categoria do pensamento. O texto vai discorrer e demonstrar a passagem, a ruptura que se dá entre o sujeito do cogito e o sujeito do inconsciente.
\end{abstract}

Palavras-chave: Cogito. Consciente. Inconsciente. Sujeito e linguagem.

\section{From PSYCHIC DETERMINISM TO SUBJECTIVE CHOICES}

\begin{abstract}
The subject over which psychoanalysis operates is different from that of classic psychology, which centers on the study of mental faculties. Subjectivity, based in the consciousness, is where the I is manifest. This way of seeing the subjective, with reference to the predominance of consciousness, was an element of $19^{\text {th }}$ century psychological discourse. From that same vein comes the Cartesian cogitation: "I think, therefore I am". This vision of man yokes the category of existence to the category of thought. The article will discuss the rupture that occurs between the subject of the cogitation and the subject of the unconscious.
\end{abstract}

Keywords: Cogitation. Conscious. Unconscious. Subject and language.

\footnotetext{
^ Doutora em Filosofia pela Universidade de Paris 8. Professora adjunta do Departamento de Psicologia Clínica/IP/UnB. Membro da Associação Brasileira de Estudos Sobre o Bebê. Membro da Escola de Psicanálise dos Fóruns do Campo Lacaniano. Psicanalista.

E-mail: dchatelard@terra.com.br
} 
O sujeito sobre o qual operamos na psicanálise é diferente daquele da psicologia clássica que se centrava nos estudos das faculdades mentais e estava, também, identificado com o ser da consciência. Dito de outro modo, a subjetividade estava fundada na consciência e nela se inscreveria o Eu (BIRMAN, 2003, p. 8). Essa visão do subjetivo, a referência à consciência como soberana, fazia parte do discurso psicológico vigente no século XIX. ${ }^{1}$

Na mesma veia corre a tradição cartesiana com o cogito: "Penso, logo existo". Dessa visão do homem, a categoria da existência está atrelada à categoria do pensamento. Encontramos nessa formulação o fundamento e a certeza da subjetividade.

A essa visão adicionou-se também a dita terceira ferida narcísica, introduzida para a humanidade por Sigmund Freud, tendo sido precedida historicamente pelas revoluções copernicanas na cosmologia e na biologia. Aí está a psicanálise, excluindo da cena a soberania do Eu e da consciência no psiquismo ao colocar na Outra cena o inconsciente, a spaltung do sujeito. A divisão do sujeito entre verdade e saber. Sob o apelo, lembra Jacques Lacan, do "Wo Es war, soll Ich werden", que retraduzo, mais uma vez, para acentuá-lo aqui: "Lá, onde isso estava, lá, como sujeito, devo [eu] advir" (LACAN, 1998, p. 878). Há já aí uma escolha a ser feita, escolha pelo advir, pela separação dos significantes advindos do Outro (alienação). Lacan (1998), em $A$ ciência e a verdade, ressalta a segunda oração do cogito cartesiano: "logo existo". É preciso lê-la, dirá Lacan, considerando "que o pensamento só funda o ser ao se vincular à fala, onde toda operação toca na essência da linguagem" (LACAN, 1998 p. 879); e mais adiante acrescenta ao cogito ergo a evidencia de que nada é falado senão apoiando-se na causa. "Ora, essa causa é o que é abarcado pelo Soll Ich, pelo devo [eu] da fórmula freudiana, que, por inverter seu sentido, faz brotar o paradoxo de um imperativo que me pressiona a assumir minha própria causalidade" (LACAN, 1998, p. 879). Se o inconsciente é linguagem, o sujeito, observa Lacan (1965a) no Seminário XII, não usa a linguagem, mas dela surge. "O sujeito existia onde não pensava e pensava onde não existia”. O inconsciente está fora do registro do pensamento porque é necessário algo a mais, que escape ao registro da existência atrelada ao pensamento, que é o ato eis aí uma escolha, uma escolha não pensada, mas que se faz presente no e pelo ato.

Assim, Freud(1901/1996) demonstrará no artigo "Sobre a psicopatologia da vida cotidiana" o quanto o esquecimento de nomes, as falhas na linguagem fazem parte das formações do inconsciente. O aforismo de Jacques Lacan, "O inconsciente é estruturado como uma linguagem", vem justamente revelar o surgimento da linguagem no ser falante e, estruturalmente, o quão traumático pode ter este acesso do ser vivente na linguagem. Há aí uma ruptura entre o natural e o simbólico; uma escolha a ser feita entre a vida ou a bolsa, tal como Lacan elabora no que concerne à operação de alienação e de separação; os dois tempos constitutivos da subjetividade, havendo aí uma escolha a ser feita. Assim, Freud, ao descobrir o inconsciente, propõe um rompimento com a Filosofia Moderna, na qual a razão reina, sendo a consciência soberana ao sujeito. $O$ conceito de inconsciente rompe com a noção de unidade, de domínio da razão sobre a subjetividade. 
O conceito de sujeito do inconsciente nos conduz a questionar a responsabilidade e a implicação do sujeito nas suas escolhas. Mas justamente no campo da psicanálise vamos falar de um determinismo psíquico, este determinismo poderia se confundir com certa desresponsabilidade do sujeito nas suas escolhas e posições do ser? A subjetividade é constituída de significantes que vêm do campo do Outro, certo, sendo o sujeito, então, efeito desses significantes que o dividem, surgindo somente nos intervalos de sua cadeia significante. Em que medida, então, descentrado da consciência, o sujeito em seu surgimento sempre evanescente poderia se responsabilizar por seus atos, por suas escolhas de parceiros, escolhas na vida, escolhas em sua posição sexuada e escolhas da sua morte? Uma vez que lidamos com o ser desejante da linguagem, do corpo simbólico e assim pulsional. Ou ainda, dito de outro forma, o "ente", o ser que Lacan, no início de seu ensino, aproximou ao ser heideggeriano por estar em sua constante kinésis, em seu constante movimento em direção a certa finitude, em uma palavra, em um batimento da própria pulsão de morte.

No campo da psicanálise, podemos falar de decisão em um tempo ainda mais primitivo e mítico ao sujeito vivente que há de aceder ao universo simbólico: Freud para isso refere-se à afirmação primordial, o Bejahung. Trata-se já aí de uma decisão, de uma escolha desse sujeito, de um primeiro julgamento de atribuição, no momento em que o sujeito reconhece que um primeiro significante lhe pertence e que ele deve incorporá-lo a seu ser. A inscrição necessária da Bejahung acompanha-se de uma primeira Ausstossung, expulsão, que é correlata a uma primeira negação inclusa na própria afirmação primordial. A Bejahung é uma "criação do símbolo" e concerne a uma relação do sujeito com o ser. Isso já significa que o subjetivo se inscreve em um discurso e em um laço social com o Outro da linguagem.

Assim, "por nossa posição de sujeito, sempre somos responsáveis", adverte Lacan ( 1998, p. 873) em A ciência e a verdade, abrindo o Seminário: $O$ objeto da psicanálise. Este seminário que fora precedido por "As posições subjetivas do ser". Apesar do determinismo psíquico no enlaçamento do sujeito ao campo do Outro, as contingências oferecem ao sujeito escolhas em sua sincronia temporal. Há aí uma escolha, talvez insondável, do ser em seu posicionamento ante a sua existência. Conhecemos a afirmação de Jacques Lacan no Seminário XI: "O inconsciente, mantido segundo nossa afirmação inaugural como efeito de significante e estruturado como uma linguagem, foi aqui retomado como pulsão temporal" (LACAN, 2001, p.187). Na temporalidade de uma psicanálise, o que muda e o que faz rotação de perspectiva é a relação do sujeito com a castração: a assunção da castração na experiência de uma psicanálise, de como o ser subjetiva a perda e a morte, a origem e a sexualidade. Castração que se articula à inscrição do sujeito na linguagem e marca a presença da finitude e da morte no homem. Trata-se, assim, nesse movimento da pulsão temporal, de "deixar-se perceber".

O "Um" como traço, como significante que "sutura" (LACAN, 1966, p. 39) como ausência do objeto representa o sujeito na cadeia significante. Em outras palavras, o sujeito está na cadeia ao mesmo tempo em que dela está excluído; ele existe por essa falta a partir desse vazio do objeto, esse zero que 
se conta "Um". A sutura é a "relação em geral da falta com a estrutura de que ela é um elemento, uma vez que implica a posição de um lugar-tenente" (LACAN, 2001, p. 39). No Seminário XIX: “... ou pior” Lacan atribui ao Einziger Zug, ou traço unário, o traço da própria repetição. ${ }^{3}$ Esse traço está na origem da repetição do 'Um' contável como repetição da diferença: "O traço unário, o Einziger Zug, como essência do significante, apaga toda diferença, ou seja, torna-se uma letra"4 (LACAN, 1961).

Como vimos anteriormente, o sujeito, tal como o definiu Lacan (1977), ${ }^{5}$ está dividido entre o "S1" e o "S2", entre o significante que o representa e o "S2"; ele "ex-siste" e assim insiste na cadeia. O traço unário "S1" como representação do sujeito junto a um "S2" faz deste último o efeito da repetição e da presença do "Um (S1)" recalcado. Existe "Um" no início como condição necessária, e ele se desdobra no deslizamento da cadeia, na série das repetições para que o sujeito lá possa se contar e contar. O corpo vivo só se constitui enquanto tal se corporificado pelo significante.

O "Um" tem duas funções, como assinala Lacan (1965a) no Seminário XII: Problemas cruciais para a psicanálise: “O 'Um' de miragem, que é de confundir o 'Um' com o indivíduo ou, para traduzir esse termo: o insecável, e, por outro lado, o "Um" da numeração que é outra coisa". ${ }^{6}$ Lacan (1965a) vai começar definindo o sujeito da psicanálise como a presença da falta, o sujeito instaurandose como zero. Essa definição vai permitir a Lacan estabelecer a dialética entre o que o sujeito pode ter como objeto e o objeto que ele pode ser, do qual se origina a relação do sujeito com o Outro. Entretanto, "por nossa posição de sujeito", no campo do Outro, "somos responsáveis" por essa outra cena do inconsciente que fazemos parte integrante. Além disso, no Seminário XII: Os problemas cruciais da psicanálise, de 1964-1965, Lacan trabalha a questão do sujeito na psicanálise. No ano seguinte, no Seminário dedicado ao "Objeto da psicanálise" (LACAN, 1965b), ele retoma essa questão, sob a ótica da topologia, para tratar o sujeito e o objeto da psicanálise; temos aí uma seqüência lógica, em seu pensamento, do sujeito e do objeto. No Seminário XII, primeiramente intitulado As posições subjetivas do ser, Lacan (1965a) afirma: "Ser psicanalista é uma posição responsável, a mais responsável de todas, já que ele é aquele a quem é confiada à operação de uma conversão ética radical, a que introduz o sujeito na ordem do desejo". ${ }^{7}$ O corte operado por Jacques Lacan no ontológico, mesmo sendo o da origem cartesiana, é o sujeito do inconsciente, desejante e pensante. O sujeito sofre de afânise, desaparecimento.

O psicanalista, parceiro do sujeito, é aquele que dirige a cura e, assim, visa que algo da ordem do desejo surja, levando o sujeito inevitavelmente a tocar em um ponto de angústia. $\mathrm{O}$ analista é também aquele que acolhe e deve junto com o sujeito dela tratar. A angústia, sendo a angústia de castração, é o momento privilegiado em que algo da escolha do sujeito pode surgir e por conseqüência vacilar. A angústia, quando surge, comparece no entre, na hiância, no espaço de interseção entre o sujeito e o Outro, o vazio do Outro e o vazio do sujeito se recobrem. O lugar do comparecimento da angústia é o vazio de significante. É lá exatamente o 
lugar da angústia, em que o sujeito busca responder à questão de seu ser, interrogando seu lugar na falta do Outro. E por que a existência do Outro está presente em nossa experiência subjetiva, nos resta saber que escolha dele fazer?

A partir daí, o sujeito poderá perceber seu ser de objeto, até mesmo seu ser de gozo, pois confronta-se com o que ele fora como objeto para o Outro. Assim, ele deve passar por um desvio em torno da questão de sua existência: "O que sou?" "Sou no lugar de onde se vocifera que o universo é uma falha na pureza do Não-Ser", conforme essa frase famosa que Lacan toma emprestado de Valéry para mostrar que o gozo fala - esse gozo cuja "falta tornaria vão o universo" (LACAN, 1998, p. 834). É esse gozo mesmo cuja falha torna o Outro inconsistente, esse gozo atribuído ao Outro, ainda que gozo do próprio sujeito, esse gozo que ele encontra no momento mesmo de sua destituição, no momento mesmo em que percebe seu ser de gozo. Pelo fato de que o Outro não existe "[...] só me resta imputar a culpa ao Eu [Je], isto é, acreditar naquilo a que a experiência nos conduz a todos, com Freud na dianteira: ao pecado original" (LACAN, 1998, p. 820). É isso, independentemente de nossas escolhas, que gira em torno dos três pilares da psicanálise: a origem, a sexualidade, a morte e todas as variações que delas surgem nos percalços da existência do sujeito tanto em seus encontros, quanto em seus desencontros com a presença do Outro; mas também com a inconsistência desse mesmo Outro. Só resta ao sujeito, ante o determinismo psíquico, ante a determinação da cadeia significante, ousar remanejar e subverter essa determinação na sincronia de sua existência. O sujeito faz-se presente na cadeia, de uma posição "ex-cêntrica" a ela, mesmo que inserido em um discurso e em uma narrativa sempre atemporal e fictícia. Só resta, enfim, a esse sujeito suas escolhas subjetivas e, sobretudo, que ele possa delas tirar suas conseqüências e seus atos.

\section{NOTAS}

${ }^{1}$ Trabalho apresentado no VI Encontro da Escola de Psicanálise dos Fóruns do Campo Lacaniano em novembro/2005 - RJ. As escolhas do sujeito: na vida, no sexo, na morte.

2 Este termo "sutura" é considerado por Jacques-Alain Miller (1996) como o que "nomeia a relação do sujeito com a cadeia de seu discurso".

${ }^{3}$ Aula de 10 de maio de 1972.

${ }^{4}$ Aula de 6 de dezembro, inédita.

${ }^{5}$ Aula de 15 de novembro, inédita.

${ }^{6}$ Aula de 3 de março, seminário inédito.

${ }^{7}$ Aula de 5 de maio, seminário inédito. 


\section{REFERÊNCIAS}

BIRMAN, J. Freud e a filosofia. Rio de Janeiro: J. Zahar, 2003.

FREUD, S. Sobre a psicopatologia da vida cotidiana (1901). In: Obras psicológicas completas de Sigmund Freud. Rio de Janeiro: Imago, 1996.

LACAN, J. A ciência e a verdade. In: . Escritos. Rio de Janeiro: J. Zahar, 1998. p. 869-892.

. Subversion du sujet et dialectique du désir. In: Ecrits. Paris: Seuil, 1966. p. 793-827. $\overline{\text { Seuil, } 2001 .}$

Compte Rendu do seminário de 1964. In: . Autres Ecrits. Paris:

. O Seminário IX: identificação. Inédito, 1961/1962. 1965a.

. O Seminário, livro XII: problemas cruciais da psicanálise. Inédito, 1965b.

O Seminário, livro 13: O objeto da psicanálise. Seminário não publicado, Zahar, 2003.

O Seminário, livro 19: ... ou pior. In: Outros escritos. Rio de Janeiro: J. . O Seminário XXV: o momento de concluir. Inédito,1977-1978.

MILLER, J. A. La suture. In: . Les Cahiers pour l'analyse. Val de Loire \& Bretagne: Association de la Cause Freudienne, 1996.

Recebido em: fevereiro de 2007 Aceito em: julho de 2007 